\title{
A Study on the Countermeasures to Enhance the Grass-roots Social Governance Capacity of Southern Xinjiang
}

\author{
Yongfu Bi , Zhang Aiping * \\ College of Economics and Management, Tarim University, Alar, Xinjiang, 843300, China
}

Keywords: Southern Xinjiang; Grass-roots society; Governance capability; Promotion strategy

\begin{abstract}
The ethnic issues, livelihood issues, religious issues and social stability issues in the Southern Xinjiang region are intertwined, and the grass-roots governance has some complexity and particularity. Southern Xinjiang issue is the crux of the problem in Xinjiang, and is the key to the treatment and stability of Xinjiang strategy. Promoting the governance capability of the grass-roots society in Southern Xinjiang will help to achieve social stability and long-term stability in Xinjiang. Based on the author's research results, this paper firstly analyzed the significance of enhancing the Southern grassroots social governance capacity, and then put forward some specific countermeasures to improve to in grassroots social governance capacity.
\end{abstract}

\section{Introduction}

President Xi Jinping stressed that social stability and long period of stability is a general goal of the work in Xinjiang at the second central Xinjiang work forum, and Xinjiang work must seek long-term solutions. Enhancing the Southern grassroots social governance capacity should give full consideration to the complexity and diversity of the question of Xinjiang. This is not only the policy to maintain social stability and long period of stability and reinforcing, but also the key measure to promote the construction of rural grassroots organizations and institutionalization of the rural social governance. It has accumulated significant experience for social stability and long period of stability in Xinjiang.

\section{The Significance of Enhancing the Grassroots Social Governance Capacity in Southern Xinjiang}

It is conducive to strengthen the building of grassroots political power in Southern Xinjiang. Under the traditional "control" mode, the grass-roots government is more as a performer, and the initiative can not effectively play. Strengthening the innovation of grassroots social governance can stimulate the enthusiasm, initiatives of the grassroots and the vitality of grassroots regime. Moreover, it also makes the decentralization be used by the grassroots level and gives the power to society from the basic level, so that the building of grassroots political power can be strengthened.

It is conducive to improve the overall level of Southern Xinjiang grassroots social governance and social services. At present, the Southern Xinjiang is in the critical period of the "three forces" combating ethnic separatism, religious extremism, violence and terror. At the same time, it is also the highlight of various social contradictions. The economic and social development, education, employment, medical, pension and other social problems in the field still have not been effectively resolved. It can be said that a variety of social problems and harmonious and stable issues are intertwined, and new social risks are emerging, which makes the stability of Southern Xinjiang face severe challenges. The traditional social management model is relatively unitary, which has been unable to cope with this complex situation effectively. In order to solve these problems, the "main battlefield" that solve a new social risk is at the grassroots level, and the level 
of social governance level needs to be improved. At the same time, we should strengthen the innovation of grassroots social governance.

It is conducive to enhancing the basic social autonomy and governance capacity of the Southern Xinjiang. On the one hand, the people are the creators of history, and also the main participants in the social governance at the grass-roots level. Grassroots autonomy is the foundation of social governance, and its essence is that the masses decide for themselves and deal with their own affairs. Therefore, strengthening and innovate grass-roots social governance is to necessarily enhance the ability of grassroots self-government as the starting point. On the other hand, social governance at the grass-roots level must also call for "common governance". The key is to launch all kinds of positive factors and integrate the interests of all parties and forces as much as possible under the unified leadership of the grassroots party committees, so that to participate in social governance and achieve "good governance". It will establish a good interactive relationship between government, market and society.

It is conducive to the realization of the Southern Xinjiang governance system and modernization of governance capacity. At present, there is an imbalance between economic and social development in Xinjiang and there are big gap between the northern and Southern Xinjiang accompanied by the problems of lacking execution and credibility for the local governments. These problems are one of the most prominent and severe issues at the grassroots level. However, as for directly facing these problems and contradictions at the grassroots level, its strength is weak, resulting in many weaknesses and gaps in grassroots social governance. To strengthen the innovation of grassroots social governance at the grassroots level, we need to construct a social governance system covering all fields, so that to eliminate weaknesses and gaps.

\section{Promotion Strategy for Southern Grassroots Social Governance Capacity}

Establish a correct concept of grassroots social governance. First, we should set up the idea of putting people first. Grassroots social governance is directly related to the vital interests of the people; to be specifically, it is the grassroots participation in the "governance" and their "service". Only by establishing the social governance concept of people-oriented, constantly realizing and safeguarding the fundamental interests of the masses with regarding the fundamental interests of the masses as the starting point and goal of all problems, can we get their approval in the grass-roots social governance. This is a prerequisite for "co governance". Second, regarding improve people's livelihood as the basic goal of strengthening and innovation of grassroots social governance is the premise of good governance. The people's livelihood problem is the basic problem of human survival and development, which is the primary goal of social governance to solve. If the people's livelihood issues are not to be solved and improved, the social fairness and justice are difficult to guarantee, which is bound to affect the social harmony, stability and development. Based on the fact that the social contradictions in Xinjiang are prone to occur at the grassroots level and the coordination of social interests is difficult, strengthening the innovation of grassroots social governance must focus on improving people's livelihood of the masses; further, only by solving the realistic problems of the people's existence through improving the distribution of interests, coordination, compensation and mediation mechanism, can we guarantee and improve the livelihood of the people at the grassroots level. Thirdly, promoting the purchase of services will meet the demand for social services to the public. On the one hand, promoting government purchase service can meet the needs of the public service; on the other hand, it is conductive to attract all kinds of social forces to participate in grassroots social governance. In this way, the government and society can form a benign and interactive relationship and establish mechanism of sharing the interests and bearing public affairs management responsibility. At the same time, it can provide many employment after effectively meeting the needs of the public. We should establish social cooperation governance mode at the grassroots level oriented by public needs, regarding all kinds of social forces to participate as a carrier and formed by purchase service and multi center supply. We should actively explore the institutional space for grass-roots social cooperation and governance so as to "maximize social vitality and maximize social harmony". 
Strengthen the construction of grassroots social governance system. Firstly, we should strengthen the grass-roots autonomy construction to form a virtuous autonomous structure. The basis of social governance at the grass-roots level is a sound structure of self-government; on this basis, a mechanism for residents to jointly management on grass-roots public affairs was formed. However, the current grassroots autonomous organizations bear a large number of government affairs, resulting in the initiative autonomy can not function effectively. We should clearly know the relationship between "autonomous affairs" of the grassroots self-government organizations and "assist in handling government affairs" from the system, eliminating the "administrative organizations at the grassroots level", so that the grass-roots autonomous organizations can concentrate their efforts on autonomous affairs. Moreover, we should give full play to the role of the grass-roots autonomous organizations in serving the grassroots, resolving contradictions, coordinating interests and solving problems; at the same time, we should organize the public to make rational and orderly participation in grassroots social governance in accordance with the law. Secondly, we should establish and perfect the interests of the masses, and protect the interests of the mechanism mediating the contradiction. In the expression of interest demands, on the one hand, we should establish and improve public collection channels to let the public opinion expression channel more convenient and efficient through mass workstations, leading hotline, WeChat public number and other forms; on the other hand, we should learn the form of "Visiting Hui Ju "to implement the primary system that leaders are going to the grass root in Xinjiang and closely contact with the masses. In the protection of rights and interests, we should put the people's rights to subsistence and development in the first place, improve the social security system, actively promote employment, encourage entrepreneurship and promote the equalization of basic public services. In the investigation and handling of contradictions, we must establish and improve the system, form the efficient conflict investigation mediation mechanism and strengthen grassroots mediation organizations and mediation team construction, so that to improve the level and ability to resolve conflicts and disputes.

Build an orderly grassroots social governance mode. First, we should establish a pluralistic body of governance at the grassroots level with transforming the "social management" into "social governance". We must change the past single subject of government management pattern and form the "governance" pattern regarding the party committee, government and community residents as the main body. Secondly, we should actively cultivate grass-roots social organizations to ensure public participation in grass-roots social governance in an orderly manner. The development of the mainland developed provinces and cities in social organization is relatively good. To be specific, the establishment of incubation social organizations is based on "government support, civil establishment and professional management"; we should accelerate the cultivation of social organizations by means of diversified means of support, such as funds, projects, talents and places. At the same time, we should take "Yuanjiang" as an opportunity to attract talented Chinese social organizations in Xinjiang and set up a branch organization in favorable conditions, playing its leading role model, so that to promote the local social organization development. In addition, we should actively guide social organizations involved in grassroots social governance, and encourage them to provide services, so that to solve the employment and improve people's livelihood; moreover, we should reflect the demands and resolve conflicts, maintain stability, promote harmony and play a positive role in the orderly public participation in the coordination of social organizations and grassroots social governance. Third, we should draw lessons from "participatory budget" to improve the enthusiasm and effectiveness of public participation. As an important governance entity, active and effective participation of the the public is the basis for achieving good governance from the perspective of the grass-roots social governance. The problem about how to improve the enthusiasm and effect of public participation is the difficulty of grassroots social governance from the past to present; in this area, we can learn from the "participatory budget" experience. Participatory budget involved in the public interest will be given and discussed by the public, and then decided by the public. At the same time, the public budget expenditure of the government will be of supervised by the public, which will make government more open, democratic and transparent. 
For grassroots social governance, we can implement "participatory governance" and participatory budget involved in the public interest will be decided by the public relying on the grass-roots autonomous organizations villagers committees and community committees under the guidance and organization of the party committees and governments at the grassroots level. This will also form a system to carry out, so that the enthusiasm and effect of public participation in grassroots social governance can be improved.

\section{Summary}

Viewing certain complexity and particularity of grassroots governance in Southern Xinjiang, the author thought that the Southern Xinjiang grassroots social governance ability should improve from the following aspects: set up correct concept of social governance at the grassroots level; strengthen the construction of social governance system at the grassroots level; build an orderly grassroots social governance. Only by organically integrating the state, society and citizens, can we effectively strengthen the innovation of grassroots social governance and maintain social harmony and stability in Xinjiang.

\section{Acknowledgements}

Key projects of National Social Science Foundation - AStudy on the Urban and Rural Grassroots Social Governance Mechanism of Southern Xinjiang(14AZD054).

\section{References}

[1] Zhou Jianpeng, Zhang Hua. Study on the Long Term Mechanism of Social Grassroots Governance in Xinjiang under the Backgrounf of Visiting Hui Ju[J]. The CPC Yili Committee Party School Journal, 2017, (01): 16-21.

[2] Khan Kertz, Ibrahim. Analysis of Rural Social Governance Model in Xinjiang Minority Areas[J]. Rural Economy and Science and Technology, 2016, (22): 135-136.

[3] Yang Fuqiang, Wan Minggang. The Plight of Rural Social Governance in South Xinjiang, Xinjiang -- Based on Anthropological Investigation of L Village[J]. Xinjiang Social Science, 2016, (02): 144-149.

[4] Liao Zhaoyu. The Study on establishment of strategic stability in South Xinjiang city on the fulcrum[J]. Journal of Shihezi University (Philosophy and Social Science Edition), 2015, (05): 9-13.

[5] Lu Yuedong. The Construction of "Rule of Law, Rule of Virtue, Grassroots Social Governance Model of Autonomy"[J]. Red Flag Presentation, 2014, (24): 28-29.

[6] Liu Shengli. The Main Form of Xinjiang Stability Work and Challenges[J]. The Science of Leadership Forum, 2014 (15): 13-14.

[7] Jiang Zhiqiang. The Construction of Grass-roots Governance Mechanism of Social Ideas and Path[J]. Civil Affairs of China, 2013, (09): 13-15. 